\title{
RESENHA
}

\section{HAGUE, Ian. Comics and the senses: a multisensory approach to comics and graphic novels. New York: Routledge, 2014. 214p.}

\author{
IVAN LIMA GOMES \\ UNIVERSIDADE ESTADUAL DE GOIÁS (UEG)
}

Nos últimos anos, a crescente produção bibliográfica sobre HQs trouxe novos desafios aos pesquisadores da área. Interdisciplinar por excelência, os estudos de HQs precisam elaborar e mapear um conjunto de temas e abordagens que possibilitem elaborar novos problemas a seus objetos de análise. Longe de ser um processo pacífico e livre de conflitos, sugerir caminhos para as pesquisas sobre quadrinhos implica atentar a um só tempo para a abertura epistemológica introduzida por eles ${ }^{1}$ e as especificidades atinentes a cada campo do saber.

A recente obra de Ian Hague integra o conjunto de tais trabalhos, sugerindo novos caminhos à análise das HQs. Fruto de pesquisa de doutorado desenvolvida na Universidade de Chichester, sob orientação dos profs. Drs. Hugo Frey e Keith Jenkins, Comics and the senses procura entender os quadrinhos para além de seus limites gráficos e visuais. Superando estabelecido paradigma que postula serem as HQs uma mídia essencialmente visual a favor de uma "abordagem multissensorial" ancorada nos Estudos Culturais, Hague defende o argumento de que a experiência de leitura e consumo de HQs só se realiza uma vez que tal linguagem mobiliza todos os cinco sentidos.

Tal perspectiva certamente dialoga com outros trabalhos que destacam a necessidade de os quadrinhos serem compreendidos em sua condição performática, na medida em que demandam profunda interação com o leitor. Certamente é uma leitura que dialoga com trabalhos que, nos estudos de mídia, enfatizam os processos intermidiáticos de convergência midiático e de remediação, em que a construção do sentido da narrativa de dado personagem depende de sua circulação entre mídias e o diálogo com a cultura material vide os recentes casos de interação entre cinema, quadrinhos e brinquedos, por exemplo ${ }^{2}$.

\footnotetext{
${ }^{1}$ Para uma discussão em torno das problematizações em nível epistemológico que as HQs e suas formas de ver e ler introduzem ao pensamento contemporâneo, cf. SOUSANIS, Nick. Unflattering. Cambridge: Harvard University Press, 2015.

2 Para os conceitos de "remediação" e "convergência midiática", respectivamente cf. BOLTER, Jay David; GRUSIN, Richard. Remediation: understanding new media. Cambridge: MIT Press, 2000. JENKINS, Henry. Convergence culture. La cultura de la convergencia en los medios de comunicación. Barcelona: Paidós, 2008.
} 
A dimensão performática e cultural da fruição de $\mathrm{HQ}$ leva Hague a elaborar profunda crítica a leituras formalistas e essencialistas, que tendem a enfatizar a necessidade de serem elaboradas chaves de leitura semióticas que liberem acesso ao sentido da obra. Por restringirem a análise à disposição de imagens seguidas umas às outras - consolidada na hoje naturalizada expressão "arte sequencial", cunhada por Will Eisner ${ }^{3}$-, perderam de vista que os quadrinhos articulam formas de ver e ler, elaborando forma original de prática cultural. Contendo um pouco de livro e de artes plásticas, de revista e de impressão técnica, os quadrinhos dependem de formas de edição, da qualidade de papel utilizado, de tipografias específicas e de uma série de aparatos técnicos que introduzem uma dimensão performática que atinge o sensível de seus leitores.

É o que defende Hague no capítulo que abre seu livro, em que problematiza a corrente bibliografia sobre HQs e sua ênfase na representação visual. Por só fazerem sentido se compreendidos enquanto fenômeno social, "a determinação do que é ou não é $\mathrm{HQ}$ depende mais de produtores e consumidores desta mídia e menos em qualquer elemento observável ${ }^{\prime \prime}$. Para superar tal abordagem, identificada como oculocêntrica e, portanto, marcada pelo paradigma da mimesis e da representação do real, o autor desenvolverá cada um dos cinco sentidos nos capítulos subsequentes. Ao contrário de trabalho que, curiosamente, tem título muito semelhante ao da obra aqui resenhada ${ }^{5}$, Hague não procura discutir como cada sentido foi visualmente representado em quadrinhos. Antes, procura demonstrar como cada um dos cinco sentidos é mobilizado a partir dos quadrinhos e sua materialidade pelos leitores.

A opção por dedicar cada capítulo a um dos sentidos tem finalidade didática e procura explicitar algumas das maneiras como cada sentido é mobilizado quando da interação com quadrinhos. Oferecem ao leitor instigantes percepções sobre como qualidade do papel e cores atingem nossa visão (cap. 2); o som do virar de páginas, a gravação de versões em áudio de HQs ou o caráter cultural que distingue sons de animais, por exemplo (cap. 3); o impacto da materialidade de uma página de quadrinhos percebida pelo tato por meio da textura e flexibilidade do papel (cap. 4); e a introdução de gostos em HQs interativas, cujos "sistemas de cheiro" tocam nos sentidos do paladar e olfato para evocar memórias e sensações nos leitores (cap. 5).

Se é didática, a divisão dos capítulos pode soar estanque, sobretudo quando está claro que Hague defende ser a leitura de HQs um ato "multissensorial". De forma inteligente, o autor consegue dar conta de tal impasse no último capítulo, ao sugerir a aplicação do conjunto das ideias

\footnotetext{
${ }^{3}$ EISNER, Will. Quadrinhos e arte sequencial. 3a ed., São Paulo: Martins Fontes, 1999.

${ }^{4}$ HAGUE, Ian. Comics and the senses: a multisensory approach to comics and graphic novels. New York: Routledge, 2014, p. 16.

5 PELLITERI, Marco. Sense of comics. La grafica dei cinque sensi nel fumetto. Roma: Castelvecchi, 1998. O fato de o livro ou nenhum outro artigo de Pelliteri não ser mencionado no livro de Hague representa ausência digna de nota. Tal fato também foi percebido, de forma crítica, em MOURA, Pedro. Ian Hague. Comics and the senses. A multisensory approach to comics and graphic novels. Image and narrative, v. 15, n. 3, 2014, p. 121-124.
} 
desenvolvidas até aqui num estudo de caso. A obra de Alan Moore - sobretudo $V$ for Vendetta - é discutida em profundidade, buscando perceber as articulações sensoriais ali presentes.

$O$ fato de que um sentido como o olfato não se encontre tão fortemente presente na análise realizada sobre a obra de Moore é exemplo de argumento de Hague, que é atento às várias possibilidades de mobilizações dos cinco sentidos que podem se fazer presentes numa dada HQ. A pouca presença de ilustrações ao longo do livro, ainda que certamente se explique por questões editoriais e de cessão de direitos, também se encontra longe de comprometer o mérito do livro, visto ser ele justamente crítico da centralidade do visual enquanto representação.

Em resumo, Comics and the senses sugere caminhos profícuos àqueles sensíveis ao caráter social e polissêmico das HQs. Longe de soar taxativo, a obra é aberta a argumentações e aplicações das mais variadas, munindo o leitor de sugestões e ideias para que outras análises atentas ao diálogo entre materialidades e sensibilidades em perspectiva histórica e cultural possam ser futuramente desenvolvidas por pesquisadores dos quadrinhos.

\section{Sobre o autor}

Ivan Lima Gomes possui graduação em História pela Universidade Federal Fluminense (2007), mestrado em História Social pela Universidade Federal do Rio de Janeiro (2010, indicada para publicação) e doutorado em História pela Universidade Federal Fluminense (2015), onde discutiu os sentidos dos quadrinhos no Brasil e no Chile a partir de duas editoras, bem como as tensões entre arte, mercado e política presentes na linguagem das HQs. E-mail: igomes2@gmail.com.

Recebido em 07 de agosto de 2016.

Aprovado em 08 de setembro de 2016. 